\title{
Lymphocytic Esophagitis Successfully Treated by Esophageal Balloon Dilation and Topical Budesonide
}

\author{
Gabriel Becheanu, Doina Istratescu, Carmen Monica Preda, Mircea Manuc, Mircea Diculescu, Cristian Gheorghe \\ Center for Digestive Diseases and Liver Transplantation, Fundeni Clinical Institute, Carol Davila University of Medicine and Pharmacy, \\ Bucharest, Romania
}
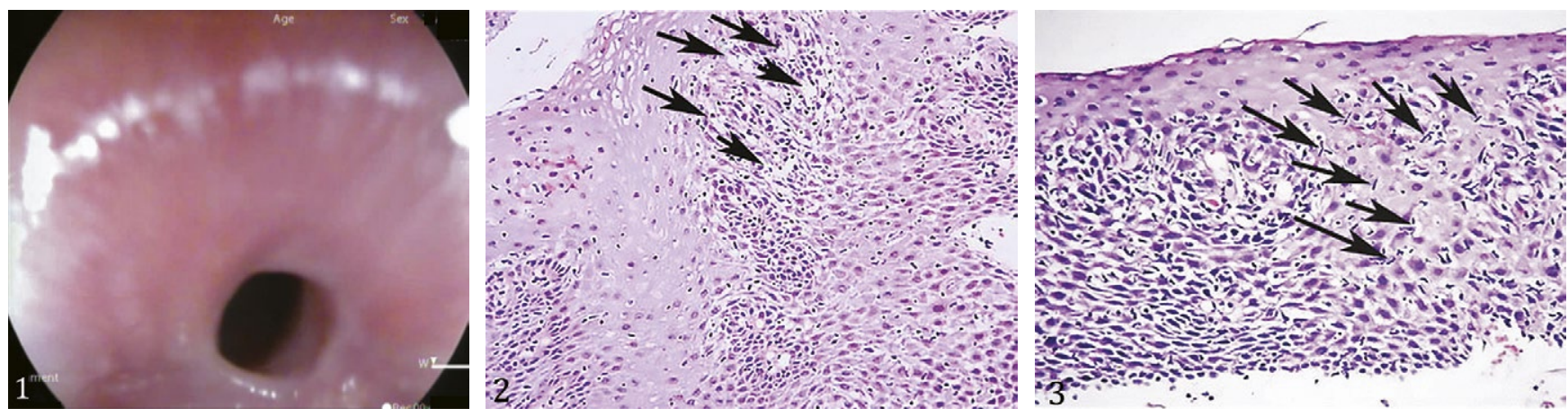

A 59-year-old female was referred to our hospital for dysphagia and significant weight loss (11 kg in 6 months). She had no significant personal or familial medical history and she was a non-smoker. The laboratory analysis showed no remarkable abnormalities. Initially, we attempted an upper gastrointestinal endoscopy without sedation, but the pharyngoesophageal junction could not be passed. The barium swallow test revealed an upper esophageal sphincter dysfunction and a filiform narrowing at this level. We attempted another gastrointestinal endoscopy with Propofol sedation, which confirmed the esophageal stenosis at the pharyngo-esophageal junction (Fig. 1) with normal overlying mucosa. Multiple endoscopic biopsies were taken from the upper and lower esophagus and an 8-9-10 mm Hercules balloon dilation was also performed. The histopathological examination showed normal architecture of the squamous epithelium, intraepithelial lymphocytosis, peripapillary spongiosis, with many „squiggle cells” (see arrows) (Figs. 2 and 3, H\&E 100x and 200x), suggestive for lymphocytic esophagitis (LE). The patient received oral topical steroids (Budesonide $400 \mathrm{mcg}$ twice daily) for three months with weight improvement and symptoms amelioration at follow-up.

Lymphocytic esophagitis is a rare condition of the esophagus, first described in 2006. It is histologically characterized by $>20$ intraepithelial lymphocytes per high-power field and rare granulocytes [1]. It affects older women in their sixth decade, smokers, and presents with gastroesophageal reflux disease or primary esophageal motility disorders [2]. The most common symptom is dysphagia, but patients can also present with heartburn, chest pain, nausea or abdominal pain [4]. Endoscopic findings vary from normal mucosa to esophageal rings, strictures, furrows and webs $[1,3,4]$. Currently, no clear treatment guidelines have been proposed for LE management. Proton-pump inhibitors and topical corticosteroids are reported to induce histological remission in these patients, as well as endoscopic therapy in the case of dysphagia and non-response to the previous treatment $[3,5,6]$.

Corresponding author: Doina Istratescu, doina.proca08@gmail.com

Conflicts of interest: None to declare.

\section{REFERENCES}

1. Rubio CA, Sjödahl K, Lagergren J. Lymphocytic esophagitis: a histologic subset of chronic esophagitis. Am J Clin Pathol 2006;125:432-437.

2. Rouphael C, Gordon IO, Thota PN. Lymphocytic esophagitis: Still an enigma a decade later. World J Gastroenterol 2017;23:949-956. doi:10.3748/wjg.v23.i6.949

3. Figueiredo PC, Pinto-Marques P, Borralho P, Freitas J. Unusual cause for smoldering dysphagia. Lymphocytic esophagitis. Dysphagia 2014;29:283-285. doi:10.1007/s00455-013-9489-2

4. Mandaliya R, Dimarino AJ, Cohen S. Lymphocytic esophagitis mimicking eosinophilic esophagitis. Ann Gastroenterol 2012;25:355-357.

5. Cohen S, Saxena A, Waljee AK, et al. Lymphocytic esophagitis: a diagnosis of increasing frequency. J Clin Gastroenterol 2012;46:828-832. doi:10.1097/MCG.0b013e3182500de8

6. Miehlke S, Madisch A, Karimi D, et al. Budesonide is effective in treating lymphocytic colitis: a randomizeddouble-blind placebocontrolled study. Gastroenterology 2009;136:2092-2100. doi:10.1053/j. gastro.2009.02.078 